\title{
Ultrasonological Findings in Multifidus Muscle in Chronic Back Pain Patients
}

\author{
Bindu Vijayalakshmi Balan' ${ }^{1}$ Mohanraj Manjalavil², Shehadad Kammili ${ }^{3}$
}

1, 2, 3 Department of Physical Medicine and Rehabilitation, Government Medical College, Kozhikode, Kerala, India.

\section{ABSTRACT}

\section{BACKGROUND}

Chronic low back pain is a major health problem which has a negative physical, social and psychological impact on the patient and their family. Chronic low back pain is defined as pain that lasts for more than 3 months duration. We can ultrasonologically assess the spinal stabilizers in a given population and come to a common decision regarding their proper strengthening and rehabilitation. We wanted to assess the ultrasonological finding in lumbar multifidus muscle in chronic low back pain patients and to compare the findings with those who are not suffering from chronic low back pain.

\section{METHODS}

The case control study included 64 cases with chronic low back pain (excluding those with structural deformities, infective, traumatic, and inflammatory aetiology) and 64 controls without low back pain, among the persons who presented to the OPD of PMR Department, Govt. Medical College, Kozhikode, Kerala. The crosssectional area as well as the percentage fatty infiltration of lumbar multifidus muscle at L4, L5 levels were assessed ultrasonologically after obtaining the consent. SPSS data analyser was used to statistically assess the variables.

\section{RESULTS}

The study population consisted of $53 \%$ females and $47 \%$ males with a comparable age group. The study showed persons with chronic low back pain had lower mean value of cross-sectional area (CSA) and higher mean value of percentage fatty infiltration in lumbar multifidus muscle at L4, L5 levels when compared to the values in persons without chronic low back pain. The CSA was significantly dependent on type of occupation they were involved. CSA was also found to be greater among males. CSA statistically showed direct relation to height and weightof the person

\section{CONCLUSIONS}

The mean CSA of lumbar multifidus is lower in persons with chronic low back pain as compared to persons without low back pain. The CSA was significantly dependent on type of occupation.

\section{KEY WORDS}

Chronic Low Back Pain (LBP), Multifidus Muscle, Cross Sectional Area (CSA), Rehabilitation.
Corresponding Author: Dr. Shehadad Kammili, Kammili (H), PO-Atholi, Kozhikode-673315, Kerala, India.

E-mail:drshehadad@gmail.com

DOI: 10.14260/jemds/2022/11

How to Cite This Article: Balan BV, Manjalavil $M$, Kammili $S$. Ultrasonological findings in multifidus muscle in chronic back pain patients. J Evolution Med Dent Sci 2022;11(01):55-60, DOI: 10.14260/jemds/2022/11

Submission 15-12-2021,

Peer Review 21-12-2021,

Acceptance 14-01-2022,

Published 24-01-2022.

Copyright (C) 2022 Bindu Vijayalakshmi Balan et al. This is an open access article distributed under Creative Commons Attribution License [Attribution 4.0 International (CC BY 4.0)] 


\section{BACKGROUND}

Low back pain is defined as pain between the coastal margins and inferior gluteal fold. ${ }^{1}$ The strength of the lumbar spine results from the size and arrangements of the bones, as well as from the arrangement of the ligaments and muscles.

Spinal health depends on optimal back muscle performance, and is determined by muscle structure and function. The multifidi are deep muscles and tiny segmental stabilizers that act to control lumbar flexion because they cannot produce enough force to truly extend the spine. ${ }^{2}$

The most important function of multifidi has been hypothesized to be that of a sensory organ to provide proprioception for the spine, and this hypothesis is supported histologically by the predominance of muscle spindles seen these muscles. Multifidi are thickest and most developed in the lumbosacral region. ${ }^{3}$

Low back pain (LBP) is often associated with dysfunction of multifidus muscle. Structural abnormalities like reduction in size and increase in fat infiltration of the muscle can be seen along with such dysfunction and can be the cause of such dysfunction. These changes lead to reduction in spinal flexibility and stability and lead to compensatory mechanisms in other joints such as the hip joint. ${ }^{4}$ They can be observed by USG which can be helpful in diagnosis and management.

Back muscles are critical for spinal stability and they play an important role in the generation of low back pain and muscular endurance ${ }^{5}$ is more important than absolute muscle strength for most patients. Alterations in proprioception ${ }^{6}$ seem to be the possible causes of alteration of postural balance in individuals with low back pain. Whether structural characteristics of the muscles are related to production of back pain is an important question to be answered. Pain intensity and functional disability index was significantly correlated with muscle size in low back pain (Nahid Rehmani et al. 2017). ${ }^{7}$ Fat infiltration of multifidus muscle was increased in chronic low back pain patients. However, there were conflicting evidences for a relationship between multifidus fat infiltration andLBP, as reviewed by Tom A Ranger ${ }^{8}$ and Fereshteh Rezazadeh et al. who found that there was no significant relationship between multifidus muscle's CSA or thickness and disability index score. ${ }^{9}$

Ultrasound imaging of the lumbar multifidus muscle is useful both for clinical and research purposes- as an objective assessment tool for detecting abnormalities and monitoring changes during recovery ${ }^{10}$ (Hides et al. 1994, 1996); and for visual biofeedback during re-education of muscle contraction (Hides et al. 1998). The characteristics of multifidus for which normal data are available include crosssectional area, linear measurements and shape. Measurement of muscle size using ultrasound has provided an accurate assessment of muscle wasting in various muscles ${ }^{11}$ (Stokes et al.). The technique was also useful in demonstrating that multifidus size does not recover ${ }^{12}$ when pain subsides unless it undergoes specific exercises (Hides et al.).

When imaging multifidus, it is important to understand its functional anatomy, the main feature which is the segmental arrangement of its fibres (Macintosh et al. 1986)..$^{13}$ Multifidus has both movement and stabilising roles. Working bilaterally with the other lumbar muscles, multifidus helps in extension of the lumbar spine and acts as a stabilizer in rotation, counterbalancing the flexion force produced simultaneously with rotation by the oblique abdominal muscles. ${ }^{13}$ Knowledge of this functional anatomy assists in imaging the muscle and using various manoeuvres for biofeedback.

Rehabilitative ultrasound imaging can be used to assess muscle activation by measuring the change in muscle geometry during contraction. The most common measurement utilized to assess muscle activation is change in muscle thickness. ${ }^{14}$ Fatty infiltration of multifidus was not affected by posture although it was increased in patients with chronic low back pain. ${ }^{15}$

\section{Objectives}

1. Assess the cross-sectional area and fatty infiltration of lumbar multifidus muscle in chronic low back pain patients at L4, L5 levels.

2. To compare the results with the parameters observed in persons without low backpain.

\section{METHODS}

This case control study was conducted from March 2019 to September 2019. Patients who presented with low back pain for more than 3 months duration and age matched persons without low back pain attending PMR Department, Govt Medical College, Kozhikode were included in the study. 64 cases and 64 controls were selected.

\section{Sampling Procedure}

In the master study, standard deviation was found to be 0.35 Using formula-

$\left(Z_{\alpha}+Z_{\beta}\right) \times S D^{2} \times 2 d^{2}$

\section{Inclusion Criteria}

1. Male and female patients attending PMR OPD.

2. Age between 30 to 50 yrs.

3. Person with low back pain for more than 3 months.

4. Age matched persons without low back pain.

\section{Exclusion Criteria}

1. Patients diagnosed with spinal neoplasm, spinal tuberculosis, spinal trauma, inflammatory arthritis and, spina bifida and ankylosing spondylitis on preliminary $\mathrm{X}$ ray, L-S spine.

2. Non ambulant patients.

3. Persons with structural abnormalities.

4. Patients with decompensated cardiovascular abnormalities.

\section{Study Tools}

1. Ultrasound machine.

2. Semi structured proforma to collect data.

3. Visual analogue scale. 


\section{Ethical Clearance}

The study protocol was submitted to institutional research committee as well as institutional ethics committee of Government Medical College, Kozhikode and clearance was obtained for conducting the study.

Male and female patients in the age group of 30 to 50 years attending PMR OPD with complaints of chronic low back pain (cases -Group A) and healthy persons attending PMR Dept without any previous history of chronic low back pain (controls-Group B) who met the inclusion criteria were enrolled in the study. Preliminary X-rays were taken for all patients so that those with exclusion criteria were excluded. Elderly patients were not included in the study because age related changes in images will make comparisons difficult. Informed written consent was taken from both the groups. Real time ultrasonological screening of spine was done in both these groups and cross-sectional area and fatty infiltration of lumbar multifidus muscle on both sides of L4 and $\mathrm{L} 5$ vertebrae was assessed.

Patients with low back pain were also assessed using Visual Analogue Scale for pain.

Height, weight and type of occupation of the study group was also recorded during the study.

\section{Procedure of Ultrasound Scanning}

The subject was laid in prone position with the forehead resting over a folded surgical towel, head in the midline and arms by the side. One or two pillows were placedunder the hips to obliterate the lumbar lordosis. The spinous processes were palpated and marked with a skin marking pen. The spinous process of L5 was identified by palpating cranially from the sacrum. It is a deep, small, blunted bony point lying at the centre of the lumbosacral depression. The spinous process of L4, which is described as comparatively large and sagittal ridged eminence, was identified by palpating cranially from L5. The images were thus obtained at the L4 and L5 spinous process levels. An ultrasound scanner was used with a $12 \mathrm{MHz}$ linear transducer. The transducer was first placed longitudinally over the lower lumbar spine, in the mid-line, to confirm the marks on the skin. The transducer was then rotated through. 90 degrees to lie transversely in the midline and the spinous processes and laminae were identified on a cross-sectional scan. The transducer was then moved laterally to each side to image the left and right multifidus muscles. The echogenic vertebral laminae were used as a consistent landmark to identify the deep border of the muscle. Images were captured, stored and measured using an ultrasound image and analysis system.

The ultrasound appearance of healthy muscle is usually dark, due to its excellent perfusion and resultant high fluid content. The presence of fatty infiltration, fibrous changes, or scar tissue (noncontractile tissue) leads to a change in its sonographic appearance, as noncontractile tissue is hyperechoic, making muscle appear whiter. Lumbar multifidus muscle atrophy appears to be a common finding in patients with chronic LBP.

\section{Statistical Analysis}

All data were coded and entered in Microsoft Excel sheet, rechecked and analysed using SPSS version 20 software. For the assessment of variables,independent $t$ test and one way ANOVA was performed.

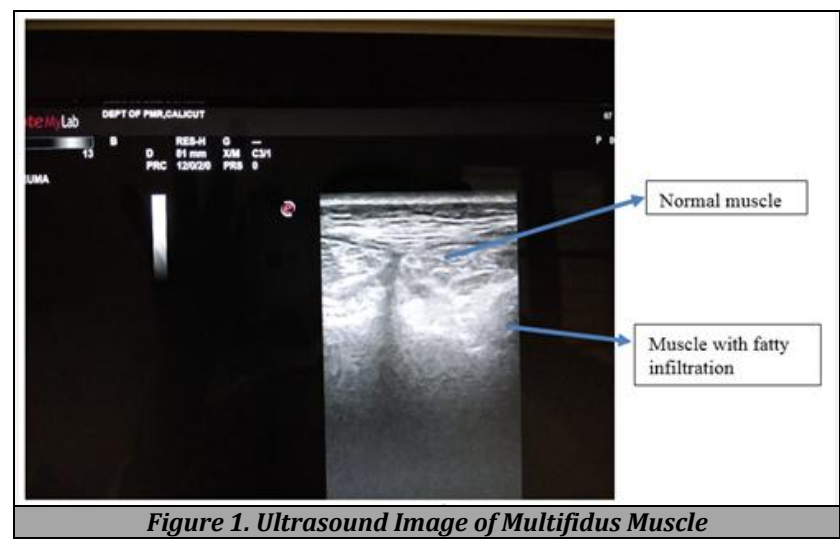

\section{RESULTS}

\section{Gender}

In the study sample of the total population of 128,68 were females (53\%) and 60 were males (47\%).

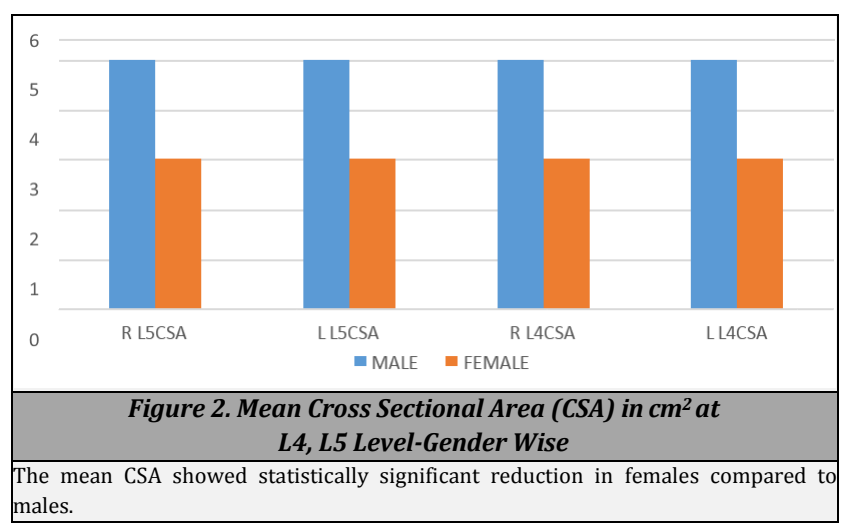

\section{LBP}

For each level the values of cross-sectional area was compared with the presenceand absence of pain:

At all levels it was found that mean CSA of multifidus in males with chronicLBP is lower than males without pain, but no significant difference among females.

When population was taken as a whole, the group with LBP showedmultifidus muscle thinning.

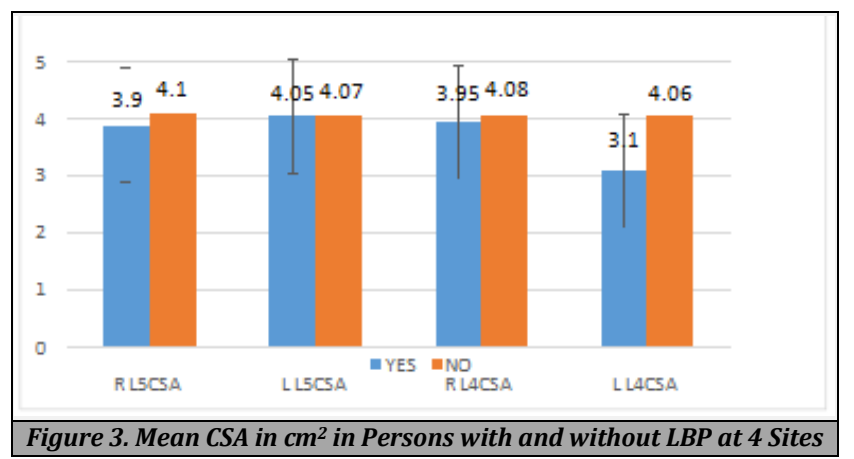




\begin{tabular}{|cccccc|}
\hline LBA & N & Mean & Std. Deviation & Std. Error Mean & P value \\
CSA L5 (R) Yes & 64 & 3.9655 & 1.13064 & .14133 & 0.05 \\
No & 64 & 4.1064 & 1.29657 & .16207 & \\
CSA L5 (L) Yes & 64 & 4.0492 & 1.06792 & .13349 & 0.014 \\
No & 64 & 4.0711 & 1.31273 & .16409 & \\
CSA L4 (R) Yes & 64 & 3.9516 & 1.09906 & .13738 & 0.032 \\
No & 64 & 4.0884 & 1.27801 & .15975 & \\
CSA L4 (L) Yes & 64 & 3.9938 & 1.06843 & .13355 & 0.032 \\
No & 64 & 4.0602 & 1.28694 & .16087 & \\
\hline \multicolumn{5}{c|}{ Table 1. Mean CSA vs LBA in Whole Population } \\
\hline \multicolumn{7}{c}{}
\end{tabular}

When the relation between the chronic low back pain and cross-sectional area was assessed at all levels the mean cross-sectional area is smaller in low back pain persons with a significant $P$ value.

\section{Occupation}

Occupation was categorised into mild, moderate and heavy according to the criteria by Food and Agricultural Organization of the United Nation. ${ }^{16}$

\begin{tabular}{|ccccc|}
\hline $\begin{array}{c}\text { (I) } \\
\text { Occupation }\end{array}$ & $\begin{array}{c}\text { (J) } \\
\text { Occupation }\end{array}$ & $\begin{array}{c}\text { Mean } \\
\text { Difference (I-J) }\end{array}$ & Std. Error & Sig. \\
Mild & Moderate & -.23712 & .36206 & .790 \\
& Heavy & -1.43873 & .45198 & .005 \\
Moderate & Mild & .23712 & .36206 & .790 \\
& Heavy & -1.20161 & .31569 & .001 \\
Heavy & Mild & 1.43873 & .45198 & .005 \\
& Moderate & 1.20161 & .31569 & .001 \\
\hline & Table 2. Mean CSA Based on Type of Occupation \\
\hline
\end{tabular}

There was significant difference in the CSA in people doing mild physical exertion and in those involved in heavy physical exertion ( $P$ value - 0.005). Similarly, there was significant difference in CSA between those involved in moderate as well as heavy physical exertion ( $P$ value -0.001). The difference between persons involved in mild and moderate physical exertion was not statistically significant.

When the data was related with the presence and absence of low back pain, the mean CSA was lower in heavy manual labourers with LBP as compared to heavy manual labourers without LBP. There was no much difference in CSA persons involved in moderate or mild jobs irrespective of presence or absence of LBP. Both physical exertions as noted by the type of work and presence of pain are influencing the CSA of the muscle.

\section{CSA with Respect to Type of Occupation and LBP}

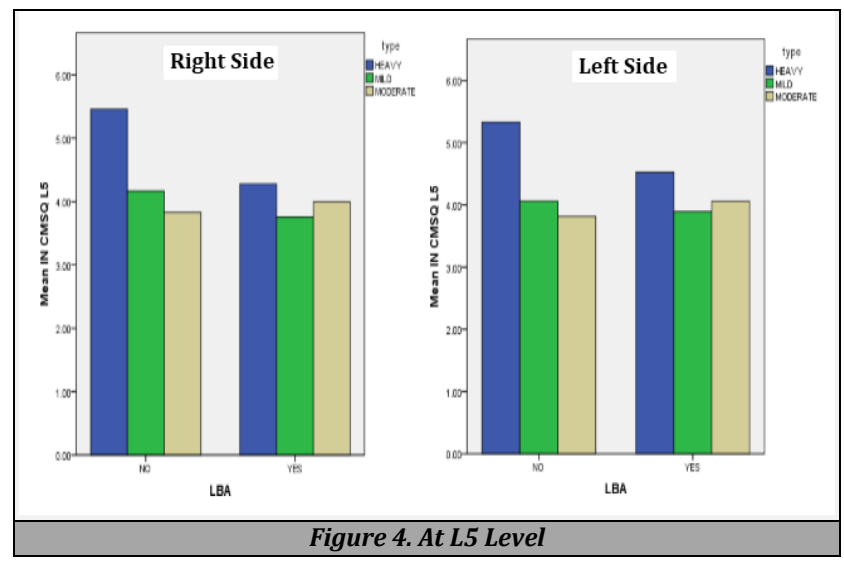

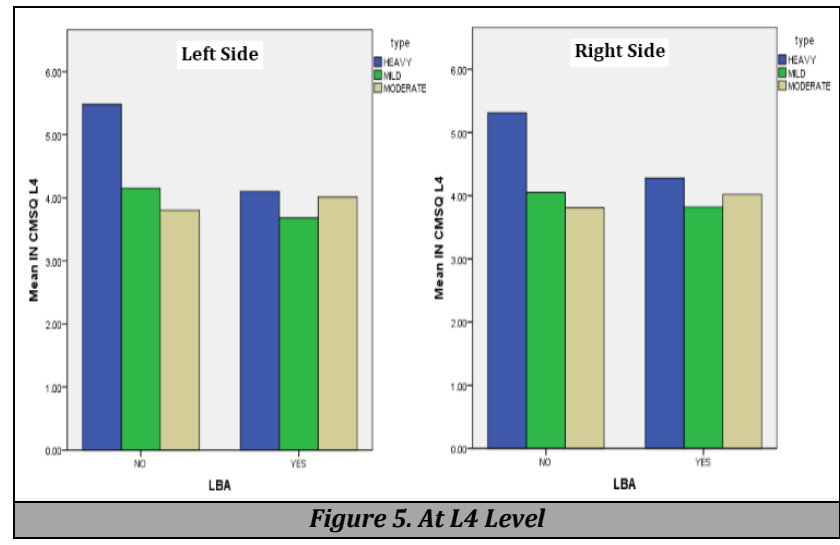

\section{Fatty Infiltration}

We performed $t$ test for fatty infiltration versus gender (P value-0.771). Mean fatty infiltration was found to be higher in males but statistically not significant.

Statistical assessment for relation between percentage fat infiltration and chronic low back pain showed the following result:

The mean fatty infiltration of lumbar multifidus muscle in the study population was higher than those with low back pain with $P$ value of 0.61 . Hence no statistical significance.

\section{VAS}

The mean VAS was found to be 2.25 in males and 2.47 in females ( $P$ value of 0.563 ) which was statistically not significant. Relation between VAS and CSA wasassessed at all levels.

The difference in multifidus CSA depending on VAS was not statisticallysignificant at any regions assessed.

\section{DISCUSSION}

This study intended at correlating the imaging characteristics of multifidus with low back pain. The mean value of CSA at L4 and L5 levels on either side was more in males compared to females irrespective of low back pain with $\mathrm{P}$ value less than 0.05 . This result matches with the study by Julie Hides et al. ${ }^{17}$ and Stokes et al. ${ }^{11}$ which showed similar results.

When descriptive analysis of CSA of males alone was observed, it was noted that mean values are lower in males with LBP as compared to males without LBP. This is in accordance with study of Julie Hides et al. ${ }^{18}$ This difference was not found in females. Mean value of CSA is higher in those involved in heavy manual labour. This, result is supported by the same study which shows that core muscle strengthening causes significant increase in lumbar multifidus muscle thickness ${ }^{18}$ and the difference in persons with heavy manual labour may be because it is associated with increased muscle exertion.

Next descriptive analysis was done to see the CSA among those with chronic LBP. It was found that, the mean value of the multifidus muscle at all levels in those involved in heavy manual labour who were suffering from chronic LBP was reduced when compared to heavy manual labourers who did not suffer from low back pain. At the same time there was no 
difference in the mean CSA between persons with and without LBP who were involved in mild or moderate type of physical exertion. The reason may be radiculopathy, which is a cause of LBP leads to multifidus atrophy as quoted in study by Hak Il Lee et al. ${ }^{19}$ When the population was taken as a whole, in persons with chronic LBP, the mean value of multifidus CSA was significantly less than in persons without chronic low LBP which was comparable with the study by Nahid rehmani et al. ${ }^{7}$ though his study population were adolescents.

Regarding fatty infiltration in relation to gender, the mean value was more in males but was without statistical significance ( $P$ value 0.771 ). The mean value of Visual Analogue Scale (VAS) was same in both males and females. The mean CSA was almost same in the study population with respect to VAS and no significant difference in mean value was observed, (P value $>0.05$ ). This result matched with the results by Rezezedah et al. ${ }^{9}$ that CSA did not change much depending on pain score and contrary to study by Nahid et al. which showed significant relation between pain scale and CSA. ${ }^{7}$

There was no statistical significance between BMI and CSA of multifidus muscle though the mean value of BMI was found to be higher among patients with chronic LBP. This matched the findings by Markus et al. ${ }^{4}$ and Stokes et al. ${ }^{11}$ where the study found weak relation only in females between BMI and CSA.

The study had shown lower mean cross-sectional area of lumbar multifidus muscle in persons with chronic LBP involved in heavy manual labour irrespective of gender. The mean value of percentage fatty infiltration of lumbar multifidus muscle was greater in persons with LBP irrespective of gender but was not statistically significant. The reference value for multifidus CSA is taken from the study by Hides et al. which is based on Western demographic features, which may differ from our study population. The mean percentage fatty infiltration and CSA of lumbar multifidus was more in males in my study sample compared to females irrespective of back pain. This study underscores the importance of proper core strengthening practices in the prevention of LBP especially in those engaged in heavy manual labour. The ultrasound imaging helps the clinician to understand the contribution of muscular pathology to the pain of the patient and plan treatment accordingly.

\section{CONCLUSIONS}

1. In persons involved in heavy manual labour, mean value of CSA was found to be less in those suffering from LBP as compared to those who did not have chronic LBP, irrespective of gender.

2. In persons involved in mild and moderate physical exertion, those with chronic LBP, showed no difference in the mean value of lumbar multifidus CSA when compared to persons without LBP.

3. Though mean fatty infiltration of lumbar multifidus muscle was noted to behigher in persons with chronic LBP in the study population, this finding was not statistically significant.

\section{Limitations of the Study}

1. Small sample size.

2. Proportion of males and females was not equal.

Data sharing statement provided by the authors is available with the full text of this article at jemds.com.

Financial or other competing interests: None.

Disclosure forms provided by the authors are available with the full text of this article at jemds.com.

\section{REFERENCES}

[1] Chou R. Low Back Pain (Chronic). Am Fam Physician 2011;84(4):437-8.

[2] Freeman MD, Woodham MA, Woodham AW. The role of the lumbar multifidus in chronic low back pain: a review. PMR 2010;2(2):142-6.

[3] Lonnemann ME, Paris SV, Gorniak GC. A morphological comparison of the human lumbar multifidus by chemical dissection. J Man Manip Ther 2008;16(4):E84-92.

[4] Hildebrandt M, Fankhauser G, Meichtry A, et al. Correlation between lumbar dysfunction and fat infiltration in lumbar multifidus muscles in patients with low back pain. BMC Musculoskelet Disord 2017;18(1):12.

[5] Süüden E, Ereline J, Gapeyeva H, et al. Low back muscle fatigue during Sørensen endurance test in patients with chronic low back pain: relationship between electromyographic spectral compression and anthropometric characteristics. Electromyogr Clin Neurophysiol 2008;48(3-4):185-92.

[6] Ito T, Sakai Y, Morita Y, et al. Proprioceptive weighting ratio for balance control in static standing is reduced in elderly patients with non-specific low back pain. Spine (Phila Pa 1978) 2018;43(24):1704-9.

[7] Rehmani N, Kiani A, Mohseni-Bandpie MA, et al. Multifidus muscle size in adolescents with and without backpain using ultrasonography. J Bodyw Mov Ther 2018;22(1):147-51.

[8] Ranger TA, Cicuttini FM, Jensen TS, et al. Are the size and composition of the paraspinal muscles associated with low back pain? A systematic review. Spine J 2017;17(11):1729-48.

[9] Rezazadeh F, Taheri N, Okravi SM, et al. The relationship between cross sectional area of multifidus muscle and disability index in patients with chronic non-specific low back pain. Musculoskelet Sci Pract 2019;42:1-5.

[10] Hides J, Richardson C, Jull G, et al. Ultrasound imaging in rehabilitation. Aust $\mathrm{J}$ Physiother 1995;41(3):187-93.

[11] Stokes M, Rankin G, Newham DJ. Ultrasound imaging of lumbar multifidus muscle: normal reference ranges for measurements and practical guidance on the technique. Man Ther 2005;10(2):116-26.

[12] Hides JA, Richardson CA, Jull GA. Multifidus muscle recovery is not automatic after resolution of acute, firstepisode low back pain. Spine 1996;21(23):2763-9.

[13] Macintosh JE, Bogduk N. The biomechanics of the lumbar multifidus. Clin Biomech (Bristol, Avon) 1986;1(4):205-13. 
[14] Stokes M, Hides J, Elliott J, et al. Rehabilitative ultrasound imaging of the posterior paraspinal muscles. J Orthop Sports Phys Ther 2007;37(10):581-95.

[15] Chan ST, Fung PK, Ng NY, et al. Dynamic changes of elasticity, cross sectional area and fat infiltration of multifidus in different postures in men with chronic low back pain. Spine J 2012;12(5):381-8.

[16] Energy requirement of adults. fao.org/3/y5686e/y5686e07.htm.

[17] Hides J, Gilmore C, Stanton W, et al. Multifidus size and symmetry among chronic LBP and healthy asymptomatic subjects. Man Ther 2008;13(1):43-9.
[18] Hides JA, Stanton W, McMahon S, et al. Effect of stabilization training on multifidus muscle crosssectional area among young elite cricketers with low back pain. J Orthop Sports Phys Ther 2008;38(3):101-8.

[19] LeeHI, Song J, Ryu JS, et al. Association between crosssectional areas of lumbar muscles on magnetic resonance imaging and chronicity of low back pain. Ann Rehabil Med 2011;35(6):852-9. 